\title{
Bioatividade de ácidos húmicos: efeitos sobre o desenvolvimento radicular e sobre a bomba de prótons da membrana plasmática ${ }^{(1)}$
}

\author{
Arnoldo Rocha Façanha(2), Anna Lvovna Okorokova Façanha ${ }^{(2)}$, Fábio Lopes Olivares ${ }^{(2)}$, Fernando Guridi(3), \\ Gabriel de Araújo Santos ${ }^{(4)}$, Ary Carlos Xavier Velloso(5), Victor Marcos Rumjanek ${ }^{(6)}$, Felipe Brasil(4), \\ Jan Schripsema ${ }^{(7)}$, Raimundo Braz-Filho(7), Marco Antônio de Oliveira ${ }^{(2)}$ e Luciano Pasqualoto Canellas ${ }^{(5)}$
}

\begin{abstract}
Resumo - A bioatividade de ácidos húmicos $(\mathrm{AH})$ isolados de lodo da estação de tratamento de esgoto (AHL) e de vermicomposto (AHV) foi avaliada pela ação dessas substâncias sobre o transporte de prótons através da membrana plasmática de células de raízes de café e milho e sua relação com o desenvolvimento dessas espécies. Houve estímulo da área superficial radicular em ambas as espécies cultivadas com ambos $\mathrm{AH}$, mostrando uma concentração ótima em torno de $40 \mathrm{mg} \mathrm{L}^{-1}$. Nessa condição, os tratamentos com AHL e AHV estimularam a $\mathrm{H}^{+}$-ATPase de membrana plasmática em plântulas de café e milho. Os AHL foram mais efetivos na promoção desses efeitos do que os AHV. A modificação do perfil cromatográfico dos $\mathrm{AH}$ em solução antes e após o cultivo das plântulas revelou que a interação planta-AH promoveu uma redistribuição das massas moleculares dessas substâncias, sugerindo uma dinâmica de mobilização de subunidades funcionais dos AH por exsudatos das raízes. A análise estrutural dos AH detectou a presença de grupamentos de auxina. A análise comparativa da ação desses dois AH sobre as espécies representantes de plantas monocotiledôneas (milho) e dicotiledôneas (café) apontam para a ativação da $\mathrm{H}^{+}$-ATPase de plasmalema como possível marcador metabólico de bioatividade dos ácidos húmicos.
\end{abstract}

Termos para indexação: Zea mays, Coffea arabica, lodo residual, ácidos orgânicos, vermicomposto.

\section{Humic acids bioactivity: effects on root development and on the plasma membrane proton pump}

\begin{abstract}
The bioactivity of humic acids (HA) isolated from sludge of the station of sewer treatment (HAL) and from vermicompost (HAV) was evaluated through the action of those substances on primary transport of protons of the plasma membrane of coffee and corn root cells and its relationship with the development of those species. A stimulation in the superficial area of roots was observed for both species cultivated with both humic acids, exhibiting an optimum concentration, about $40 \mathrm{mg} \mathrm{L}^{-1}$ of HA. In this condition the treatment with HAL and HAV stimulated the plasma membrane $\mathrm{H}^{+}$-ATPase of corn and coffee roots. HAL were more effective to promote those effects than HAV. The modification of the chromatographic profile of the HA in solution before and after the cultivation of the seedlings revealed that the interaction plant-HA promoted a rearrangement of the average molecular weight of those substances suggesting a dynamic mobilization of bioactive subunits of the HA by plant exudates. The structural analysis of the HA has detected the presence of auxin groups. A comparative analysis of the action of those HA on the monocotyledonous (corn) and dicotyledonous (coffee) plants indicates to the activation of plasmallema $\mathrm{H}^{+}$-ATPase as a possible metabolic marker for bioactivity of humic acids.
\end{abstract}

Index terms: Zea mays, Coffea arabica, sewage sludge, organic acids, vermicomposting.

\footnotetext{
(1) Aceito para publicação em 17 de dezembro de 2001 .

(2) Universidade Estadual do Norte Fluminense (Uenf), Centro de Biotecnologia e Biociências, Av. Alberto Lamego, 2000, CEP 28015-620 Campos dos Goytacazes, RJ. E-mail: arnoldo@uenf.br, anna@uenf.br, fabio@uenf.br, deoliveirama@yahoo.com.br

(3) Universidad Agraria de La Habana, San José de Las Lajas, La Habana, Cuba. E-mail: fguridi@ishc.edu.cu
}

(4) Universidade Federal Rural do Rio de Janeiro (UFRRJ), Dep. de Solos, km 47, Antiga RJ-SP, CEP 23851-970 Seropédica, RJ. E-mail: gasantos@ufrrj.br, febrasil@bol.com.br

(5) Uenf, Centro de Ciências e Tecnologias Agropecuárias. E-mail: canellas@uenf.br

(6) UFRRJ, Dep. de Química. E-mail: rumjanek @ufrrj.br

(7) Uenf, Centro de Ciência e Tecnologia. E-mail: jan@uenf.br, braz@uenf.br 


\section{Introdução}

As substâncias húmicas $(\mathrm{SH})$ participam de importantes reações que ocorrem nos solos, influenciando a fertilidade pela liberação de nutrientes, pela detoxificação de elementos químicos, pela melhoria das condições físicas e biológicas (Santos \& Camargo, 1999) e pela produção de substâncias fisiologicamente ativas (Guminski, 1968). Vários trabalhos têm demonstrado que as $\mathrm{SH}$ podem influenciar a acumulação de nutrientes e o crescimento vegetal (Vaughan \& Malcolm, 1985). Os efeitos das SH sobre o metabolismo das plantas foram resumidos por Nannipieri et al. (1993) como resultado (i) da influência positiva sobre o transporte de íons facilitando a absorção; (ii) do aumento da respiração e da velocidade das reações enzimáticas do ciclo de Krebs, resultando em maior produção de ATP; (iii) do aumento no conteúdo de clorofila; (iv) do aumento na velocidade e síntese de ácidos nucléicos; (v) do efeito seletivo sobre a síntese protéica; (vi) do aumento ou inibição da atividade de diversas enzimas. Todavia, os alvos moleculares primariamente envolvidos nessas respostas não foram ainda elucidados.

$\mathrm{O}$ incremento da absorção de nutrientes proporcionado pela presença de $\mathrm{SH}$ em solução tem sido justificado por um hipotético aumento da permeabilidade da membrana plasmática (MP) por meio da ação surfactante das $\mathrm{SH}$ e a ativação da $\mathrm{H}^{+}$-ATPase de MP (Varanini et al., 1993). Entretanto, seria improvável que o aumento da permeabilidade da MP e a dissipação do potencial transmembranar possa induzir qualquer efeito benéfico sobre as plantas. O controle da permeabilidade celular está intimamente relacionado à manutenção da seletividade da $\mathrm{MP}$, fator fundamental para a manutenção da homeostase celular. Por outro lado, o gradiente eletroquímico gerado pela $\mathrm{H}^{+}$-ATPase de MP está diretamente envolvido com dois mecanismos fundamentais do desenvolvimento vegetal: (i) a energização de sistemas secundários de translocação de íons fundamentais para a absorção de macro e micronutrientes e (ii) o aumento da plasticidade da parede celular para possibilitar o processo de crescimento e divisão da célula vegetal. Esse último mecanismo está relacionado com a teoria do crescimento ácido que postula que um aumento da extrusão de prótons mediado pela
$\mathrm{H}^{+}$-ATPase promove a acidificação do apoplasto, que por sua vez ativa enzimas específicas que atuam sobre a parede celular aumentando sua plasticidade e, conseqüentemente, permitindo o alongamento da célula (Rayle \& Cleland, 1992). Em ensaios in vitro foi observada a estimulação da $\mathrm{H}^{+}$-ATPase de MP em raízes de aveia, por $\mathrm{SH}$ de baixo peso molecular, extraídas de solo (Varanini et al., 1993). Anteriormente, um efeito similar havia sido relatado com relação a SH de húmus de minhocas sobre a $\mathrm{H}^{+}$-ATPase da fração microssomal obtida de raízes de milho (Nardi et al., 1991). Ensaios in vivo, com plântulas de milho tratadas com SH solúveis em água isoladas de turfas, também mostraram a estimulação da atividade da $\mathrm{H}^{+}$-ATPase associada a um aumento na absorção de $\mathrm{NO}_{3}{ }^{-}$(Pinton et al., 1999). Por outro lado, Nardi et al. (2000) encontraram forte inibição da $\mathrm{H}^{+}$-ATPase também obtida de microssomos de raízes de milho, porém tratado com $\mathrm{SH}$ de baixo peso molecular extraídas do horizonte superficial de um solo temperado. Tal discrepância foi relacionada às diferenças encontradas nas concentrações e na natureza química das SH testadas. A maioria dos trabalhos sobre bioatividade de SH têm-se concentrado nas frações solúveis em água ou de baixo peso molecular, porque essas substâncias poderiam acessar mais facilmente possíveis receptores na superfície da MP ou no interior da célula (Vaughan \& Malcolm, 1985). Já as bases bioquímicas e moleculares da bioatividade dos AH têm recebido relativamente pouca atenção, por serem SH de alto peso molecular e, conseqüentemente, de difícil penetração na parede e membranas das células. Entretanto, sabe-se que certos AH promovem o desenvolvimento vegetal numa mesma proporção, quando não superior, aos ácidos fúlvicos (SH de baixo peso molecular).

O objetivo deste trabalho foi avaliar a bioatividade de ácidos húmicos isolados de lodo de uma estação de tratamento de esgoto (AHL) e a bioatividade de um vermicomposto (AHV) sobre o transporte primário de prótons da membrana plasmática e sua relação com o desenvolvimento de raízes de plântulas de café e de milho.

\section{Material e Métodos}

Os ácidos húmicos (AH) foram obtidos de lodo da estação de tratamento de Jacarepaguá (AHL), Rio de Ja- 
neiro e de vermicomposto (AHV) produzido com esterco bovino pela ação de minhocas californianas vermelhas (Eisenia foetida). O procedimento de extração dos $\mathrm{AH}$ encontra-se detalhado em Canellas et al. (2001). Resumidamente, foi utilizado $\mathrm{NaOH} 0,5 \mathrm{~mol} \mathrm{~L}^{-1}$ como solvente, na razão solvente:resíduo orgânico de 1:10 (v:v) em atmosfera inerte de $\mathrm{N}_{2}$. A separação dos AH foi realizada com o abaixamento do $\mathrm{pH}$ da solução até $1,0 \mathrm{com} \mathrm{HCl} 6 \mathrm{~mol} \mathrm{~L}^{-1}$. A redissolução e precipitação foi repetida três vezes. Em seguida, adicionaram-se à amostra $200 \mathrm{~mL}$ de solução aquosa diluída de $\mathrm{HF}$ e $\mathrm{HCl}$, permanecendo sob agitação por 8 horas. Os AH foram lavados com água até teste negativo, com $\mathrm{AgNO}_{3}$, e, posteriormente, liofilizados. A caracterização dos $\mathrm{AH}$ foi realizada previamente nos trabalhos de Canellas et al. (2000a, 2000b). A Tabela 1 resume as principais propriedades estruturais dos $\mathrm{AH}$ estudados.

Para diminuir a polaridade, foram adicionados $10 \mathrm{~mL}$ de metanol a $30 \mathrm{mg}$ de ambas amostras de AH. As suspensões alcoólicas foram mantidas em banho de gelo sob agitação constante, e tratadas com 10 gotas de cloreto de acetila. $\mathrm{O}$ volume de cada suspensão foi reduzido em baixa temperatura, após quatro horas de reação, e o procedimento, repetido três vezes. Os produtos obtidos pela reação de metilação de $\mathrm{AH}$ foram redissolvidos em $10 \mathrm{~mL}$ de metanol (grau HPLC) e analisados por cromatografia gasosa acoplada à espectrometria de massas (CG-EM). Foram injetados 1 e $2 \mu \mathrm{L}$ das soluções num aparelho Shimadzu - QP5050A equipado com cromatógrafo gasoso com coluna DB-1 (J \& W Scientific) $30 \mathrm{~m} \mathrm{x}$ $0,25 \mathrm{~mm}$ (d.i.) e espectrômetro de massa operando com ionização por impacto eletrônico a 70 eV. As temperaturas de injeção e de detecção foram mantidas em $280^{\circ} \mathrm{C}$, e a da coluna, programada para a variação de $100^{\circ} \mathrm{C}$ a $280^{\circ} \mathrm{C}$ a $15^{\circ} \mathrm{C}$ min $^{-1}$. Foi obtido, nas mesmas condições, o cromatograma e o espectro de massas de IAA padrão previamente metilado.
A solução de $40 \mathrm{mg} \mathrm{L}^{-1}$ de AH, após padronização do teor de carbono $\left(10 \mathrm{mg} \mathrm{L}^{-1}\right)$, foi analisada antes e depois do crescimento das plântulas de milho, por cromatografia de exclusão em gel em coluna de 200 x $15 \mathrm{~mm}$ preenchida com Sephadex G-200, coletor automático, eluída com solução de $\mathrm{NaCl} 0,01 \mathrm{~mol} \mathrm{~L}^{-1}$, fluxo de $0,75 \mathrm{~mL} \mathrm{~min}^{-1} \mathrm{e}$ detecção por UV em $1=250 \mathrm{~nm}$.

Sementes de café (Coffea arabica L., var. Caturra) e de milho (Zea mays L., var. BR-106), obtidas da EmbrapaCentro Nacional de Pesquisa de Agrobiologia, foram esterilizadas por imersão numa solução de $\mathrm{NaClO} 0,5 \%$ e mantidas em água, por seis horas após a lavagem. Em seguida, as sementes foram acondicionadas em papel e germinadas no escuro a $28^{\circ} \mathrm{C}$. Quatro e 30 dias após a germinação das sementes de milho e café, respectivamente, as plântulas foram transferidas para um meio de cultura mínimo contendo somente $\mathrm{CaCl}_{2} 2 \mathrm{mmol} \mathrm{L}^{-1}$. O meio mínimo foi suplementado com AH na concentração de 0,20 , 40 e $80 \mathrm{mg} \mathrm{L}^{-1}$. O pH da solução foi ajustado para 5,5 com solução diluída de $\mathrm{NaOH}$ ou $\mathrm{HCl}$. Após sete dias de crescimento nestas soluções, as plântulas foram coletadas, as raízes, digitalizadas, e avaliados os parâmetros comprimento e área superficial por meio do software SIACS (Embrapa-Centro Nacional de Pesquisa e Desenvolvimento de Instrumentação Agropecuária), de acordo com Cruvinel et al. (1996). Outra amostra de raízes foi coletada e usada nos seguintes procedimentos experimentais: a) Preparação da fração microssomal: a fração isolada de raízes de milho e café foi obtida por centrifugação diferencial, conforme De Michelis \& Spanswich (1986). As raízes foram cortadas e pesadas, e então, homogeneizadas em meio tamponado em almofariz. $\mathrm{O}$ tampão de extração foi composto de sacarose $250 \mathrm{mmol} \mathrm{L}^{-1}$, glicerol a $10 \%$, DTT 3,3 $\mathrm{mmol} \mathrm{L}^{-1}, 5 \mathrm{mmol} \mathrm{L}^{-1}$ EDTA, 0,5\% de PVP-40, $\mathrm{KCl} 150 \mathrm{mmol} \mathrm{L}^{-1}$, BSA $0,13 \%$, PMSF $1 \mathrm{mmol} \mathrm{L}^{-1}$, Tris- $\mathrm{HCl}(\mathrm{pH} 8,0) 0,1 \mathrm{~mol} \mathrm{~L}^{-1}$, na relação peso de tecido/ volume de tampão de 1:2. As soluções usadas na

Tabela 1. Distribuição da intensidade de $\mathrm{C}$ nas diferentes regiões (ppm) do espectro de ressonância magnética nuclear ${ }^{13} \mathrm{C}$, composição elementar e acidez funcional de ácidos húmicos extraídos de lodo da estação de tratamento de esgotos $(\mathrm{AHL})^{(1)}$ e de vermicomposto $(\mathrm{AHV})^{(2)}$.

\begin{tabular}{|c|c|c|c|c|c|c|c|}
\hline \multirow[t]{2}{*}{ Composto } & \multicolumn{7}{|c|}{ Intensidade relativa (área total em \%) } \\
\hline & $\begin{array}{c}0-48 \\
\text { (C alifático) }\end{array}$ & $(\mathrm{C} \mathrm{de}$ & $\begin{array}{l}48-11 \\
\text { deos e }\end{array}$ & dratos) & $\begin{array}{c}110-145 \\
\text { (C aromático) }\end{array}$ & $\begin{array}{c}\text { 145-165 } \\
\text { (C fenólico) }\end{array}$ & $\begin{array}{c}165-190 \\
\text { (C carboxílico) }\end{array}$ \\
\hline AHL & 36,4 & & 19,2 & & 27,2 & 6,0 & 11,2 \\
\hline \multirow[t]{3}{*}{ AHV } & 17,5 & & 31,5 & & 41,9 & 7,4 & 8,7 \\
\hline & \multicolumn{4}{|c|}{ Composição elementar } & \multicolumn{3}{|c|}{ Acidez $\left(\mathrm{cmol}_{\mathrm{c}} \mathrm{kg}^{-1}\right)$} \\
\hline & $\% \mathrm{C}$ & $\% \mathrm{H}$ & $\% \mathrm{~N}$ & Cinza & Total & $\mathrm{COOH}$ & $\mathrm{PhOH}$ \\
\hline AHL & 54,0 & 7,0 & 4,9 & 0,74 & 574,2 & 445,0 & 129,2 \\
\hline AHV & 48,5 & 5,57 & 3,2 & 0,51 & 531,2 & 495,8 & 170,2 \\
\hline
\end{tabular}

(1)Dados compilados de Canellas et al. (2000a, 2000b). ${ }^{(2)}$ Dados compilados de Guridi (2000); ambos os espectros RMN ${ }^{13} \mathrm{C}$ foram obtidos em solução num equipamento Bruker AC 200 seqüência INVGATE com $50,3 \mathrm{MHz}$ para ${ }^{13} \mathrm{C}$. 
preparação estavam geladas, e toda a manipulação foi realizada de 0 a $4{ }^{\circ} \mathrm{C}$. $\mathrm{O} \mathrm{pH}$ foi monitorado durante a homogeneização, mantendo-se entre 7,6 e 8,0. O homogenato resultante foi então filtrado através de quatro camadas de gaze, e submetido a centrifugação a $3.000 \mathrm{~g}$ durante dez minutos para a remoção de células não rompidas e núcleos. No isolamento das mitocôndrias, o sobrenadante foi novamente centrifugado a $10.000 \mathrm{~g}$ por mais 15 minutos. O sobrenadante foi submetido à nova centrifugação, a $100.000 \mathrm{~g}$ por 40 minutos. O precipitado dessa segunda centrifugação foi solubilizado em solução tampão contendo: glicerol a $15 \%$, DTT $1 \mathrm{mM}$, PMSF $0,02 \mathrm{mmol} \mathrm{L}^{-1}$, Hepes-KOH $10 \mathrm{mmol} \mathrm{L}^{-1} \mathrm{pH}$ 7,6 e EDTA $1 \mathrm{mmol} \mathrm{L}^{-1}$, resultando numa concentração de proteína total de 8 a $12 \mathrm{mg} \mathrm{mL}^{-1}$; b) A purificação das vesículas de membrana plasmática foi realizada conforme Façanha \& De Meis (1995). Quatro mL da fração microssomal foram aplicados sobre um gradiente descontínuo trifásico de sacarose nas concentrações de 10,30 e $46 \%(\mathrm{p} / \mathrm{v})$, para preparação de raízes contendo Tris-HCl $10 \mathrm{mM}$ pH 7,6, EDTA $1 \mathrm{mM}$ e DTT $1 \mathrm{mM}$. $\mathrm{O}$ gradiente com a fração microssomal foi submetido a uma centrifugação de $100.000 \mathrm{~g}$ num rotor SW40 (Beckman), durante três horas. As bandas contendo MP foram coletadas e diluídas três vezes em água gelada e novamente centrifugadas a $100.000 \mathrm{~g}$ por 40 minutos. O precipitado foi ressuspenso num tampão contendo: glicerol a $10 \%$, DTT 1 mM, 10 mM de Tris-HCl pH 7,6 e EDTA 1 mM. A proteína total contida na preparação foi dosada segundo Lowry et al. (1951); c) A atividade ATPásica foi determinada colorimetricamente, medindo-se a quantidade de fosfato inorgânico liberado pela reação. A reação foi iniciada com a adição da proteína, e parada pela adição de ácido tricloroacético (gelado) para uma concentração final de $10 \%$ (v/v). Composição do meio reacional: MOPS-Tris pH 6,5 ou 7,0, 50 mmol L-1; $\mathrm{MgCl}_{2} 3$ a $5 \mathrm{mmol} \mathrm{L}^{-1}, \mathrm{KCl}$ $100 \mathrm{mmol} \mathrm{L}^{-1}$, ATP $1 \mathrm{mmol} \mathrm{L}^{-1}$ e $50 \mu \mathrm{g}$ de proteína. A hidrólise de ATP representa a atividade sensível a $0,2 \mathrm{mmol} \mathrm{L}^{-1}$ de vanadato.

O transporte de próton foi monitorado pelo decréscimo da fluorescência da sonda metacromática, 9-amino-6cloro-2-metoxiacridina (ACMA), excitada com feixe de $\lambda 415 \mathrm{~nm}$ e com a emissão captada a $485 \mathrm{~nm}$. O meio reacional foi composto de $10 \mathrm{mmol} \mathrm{L}^{-1}$ de MOPS-Tris $\mathrm{pH} 6,0, \mathrm{KCl} 100 \mathrm{mmol} \mathrm{L}^{-1}$, ACMA $2 \mu \mathrm{mol} \mathrm{L}-1, \mathrm{MgCl}_{2}$ $5 \mathrm{mmol} \mathrm{L}^{-1}$ e ATP $1 \mathrm{mmol} \mathrm{L}^{-1}$.

\section{Resultados e Discussão}

A composição elementar, a acidez total, carboxílica e fenólica, e a distribuição dos átomos de C para AHL e AHV mostraram semelhanças com caracterís- ticas estruturais de $\mathrm{AH}$ isolados de solos (comparando dados da Tabela 1 com os de Schnitzer \& Preston, 1986). A distribuição de estruturas carbonadas permite sugerir que os AHL são mais evoluídos estruturalmente que os AHV. Nos AHL ocorreu maior acúmulo relativo de $\mathrm{C} \mathrm{sp}^{3} \mathrm{em}$ longas cadeias alquílicas $\left(\delta_{\mathrm{C}} 0-48\right)$, menor conteúdo de $\mathrm{C}$, atribuído a polissacarídeos $\left(\delta_{C} 48-110\right)$, e maior conteúdo de $\mathrm{C}$ e de $\mathrm{N}$ na composição elementar características do processo de evolução da matéria orgânica humificada (Zech et al., 1997). A análise de CG/EM usando IAA-metilado como padrão revelou tempo de retenção (Tr) de 7,49 minutos e espectro de massa com os picos mais importantes em m/z 189, correspondendo ao íon molecular ([M].+) e m/z 130 (pico básico) (Tabela 2). Ambos os derivados metilados dos $\mathrm{AH}$ apresentaram em $\mathrm{Tr}=7,49$ minutos e pico base em m/z 130, compatível com presença do íon formado por reação de fragmentação com eliminação do radical - $\mathrm{CO}_{2} \mathrm{Me}$ e íon molecular m/z 189. $\mathrm{O}$ experimento CG/EM confirma a presença de IAA na estrutura dos AH estudados (Tabela 2).

$\mathrm{O}$ perfil cromatográfico das soluções dos $\mathrm{AH}$ após o cultivo das plântulas de milho foi fortemente alterado em ambos os AH (Figura 1). As substâncias exsudadas pelas raízes de milho parecem modificar a distribuição ou conformação dos componentes de ambos os AH. Foi postulado, por Piccolo et al. (1999),

Tabela 2. Principais picos do espectro de massas (razão massa/carga) e intensidade relativa (entre parênteses) do ácido indolacético (AIA) metilado e dos derivados metilados de ácidos húmicos isolados de vermicomposto (AHV) e de lodo da estação de tratamento de esgoto (AHL) separados por cromatografia gasosa com tempo de retenção $\left(T_{R}\right)$ de 7,5 minutos.

\begin{tabular}{lcl}
\hline Amostra & $\begin{array}{c}\text { Íon molecular } \\
\left(\mathrm{M}^{+}\right)\end{array}$ & \multicolumn{1}{c}{\begin{tabular}{c}
\multicolumn{1}{c}{ Razão massa/carga } \\
e intensidade do pico $(\%)$
\end{tabular}} \\
\hline AIA & $189(25 \%)$ & $130(100 \%)^{(1)} ; 103(5 \%) ; 78(10 \%) ;$ \\
& & $77(3 \%) ; 51(4 \%)$ \\
\hline AHV & $189(20 \%)$ & $\begin{array}{l}175(30 \%) ; 144(10 \%) ; 130 \\
(100 \%)^{(1)} ; 112(25 \%) ; 95(70 \%) ; \\
\end{array}$ \\
& & $91(45 \%) ; 77(40 \%) ; 73(70 \%) ;$ \\
& $51(49 \%)$ \\
\hline AHL & $189(5 \%)$ & $184(10 \%) ; 162(15 \%) ; 135(40 \%) ;$ \\
& & $130(100 \%)^{(1)} ; 105(40 \%) ; 91(48 \%) ;$ \\
& & $77(3 \%) ; 76(45 \%) ; 59(40 \%)$ \\
& & $51(9 \%)$ \\
\hline
\end{tabular}

(1)Pico base. 
que os AH são formados por uma mistura heterogênea de pequenas moléculas reunidas num arranjo supramolecular, estabilizado por forças relativamente fracas (ligações do tipo van de Waals, $\pi-\pi, \mathrm{CH}-\pi$ ). Essas ligações podem ser quebradas reversivelmente na presença de baixas concentrações de ácidos orgânicos (Nardi et al., 2000; Cozzolino et al., 2001). Vários ácidos orgânicos são exsudados pelas raízes de várias plantas que podem mobilizar subunidades estruturais das $\mathrm{SH}$, resultando na alteração observada do perfil cromatográfico de exclusão das amostras (Figura 1). É possível que pelo menos algumas dessas subunidades possuam atividade hormonal, tais como os grupamentos auxínicos detectados nos derivados metilados de ambos os $\mathrm{AH}$ estudados (Tabela 2). Essas subunidades funcionais, uma vez dissociadas da molécula base de $\mathrm{AH}$, poderiam acessar receptores na superfície ou no interior das células das raízes, desencadeando processos que culminariam com o estímulo do desenvolvimento em comprimento e área radicular, observado nas plântulas de milho e café (Figura 2). Essa hipótese pode explicar os relatos de atividade hormonal semelhante à auxina exibida por várias $\mathrm{SH}$, incluindo AH (Bottomley, 1917; Muscolo et al., 1998; Nardi et al., 1999). Na concentração de $40 \mathrm{mg} \mathrm{L}^{-1}$, ambos os AH exibiram o melhor desempenho na indução do desenvolvimento do sistema radicular (Figura 2). Ensaios enzimáticos utilizando vesículas de plasmalema isolados de raízes tratadas $40 \mathrm{mg} \mathrm{L}^{-1}$ de AHL ou AHV revelaram um estímulo da atividade ATPásica sensível a vanadato e do transporte de $\mathrm{H}^{+}$acoplado à hidrólise de ATP, consistente com a ativação da $\mathrm{H}^{+}$-ATPase de membrana plasmática (Tabela 3). A interação dos $\mathrm{AH}$ diretamente com a $\mathrm{H}^{+}$-ATPase não parece responder pela ativação dessa enzima, porque in vitro, a adição de ambos os $\mathrm{AH}$ ao meio de reação promoveu a inibição da atividade ATPásica (Figura 3). As atividades da $\mathrm{H}^{+}$-ATPase exibidas na Tabela 3 foram obtidas de vesículas de membrana plasmática que se formaram durante o fracionamento celular com a face citoplasmática exposta ao meio (in-side-out vesicles). Logo, parece que a hipótese mais plausível é que moléculas de $\mathrm{AH}$ ou suas
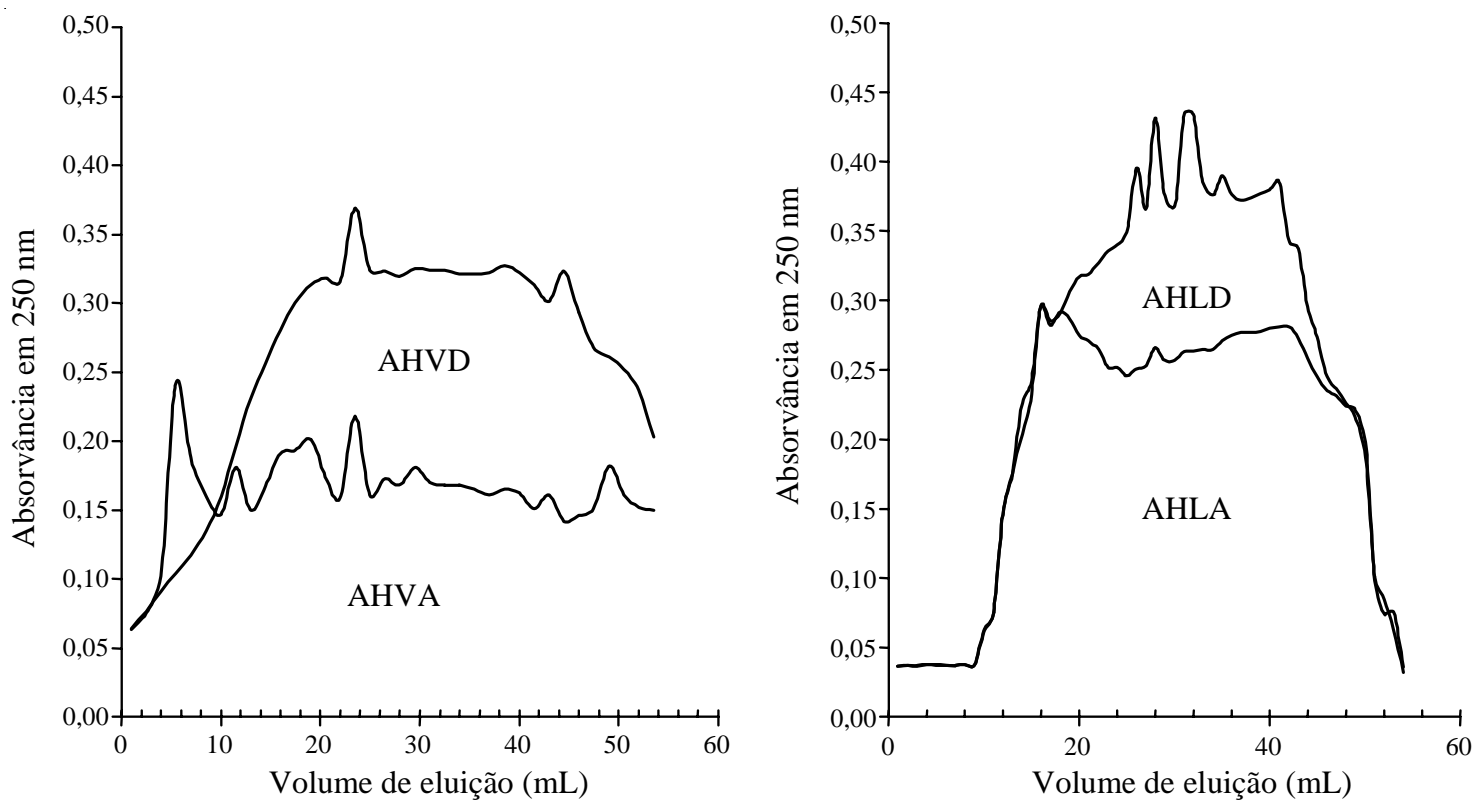

Figura 1. Cromatografia de exclusão por tamanho da solução de ácidos húmicos a pH 5,5. AHVA: ácidos húmicos isolados de vermicomposto antes do crescimento das plântulas de milho; AHVD: ácidos húmicos isolados do vermicomposto depois do crescimento de plântulas de milho; AHLA: ácidos húmicos isolados de lodo da estação de tratamento de esgoto antes do crescimento das plântulas de milho; AHLD: ácidos húmicos isolados de lodo da estação de tratamento de esgoto depois do crescimento de plântulas de milho. 
subunidades interajam com receptores na superfície celular, que, por sua vez, transmitiriam um sinal para dentro da célula, desencadeando a ativação da $\mathrm{H}^{+}$-ATPase.

Esses resultados corroboram a idéia de que a $\mathrm{H}^{+}$-ATPase de membrana plasmática seja um dos prin-

Plântulas de café
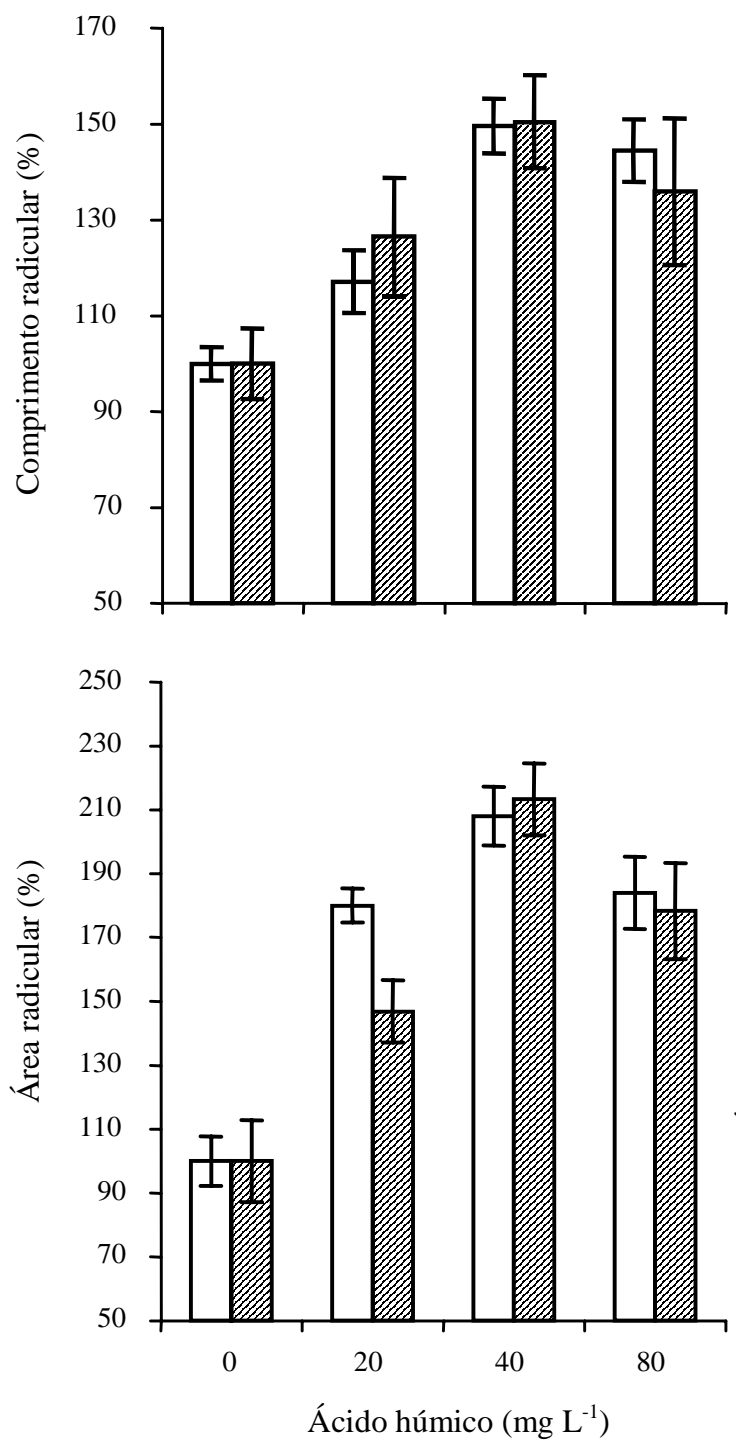

cipais alvos moleculares envolvidos na ação dos ácidos húmicos sobre o crescimento das plantas. Essa enzima é o principal sistema de transporte ativo de $\mathrm{H}^{+}$da membrana plasmática, e exerce forte efeito sobre a regulação do $\mathrm{pH}$ do apoplasto (Morsomme \& Boutry, 2000). A acidificação do apoplasto é uma pré-

Plântulas de milho
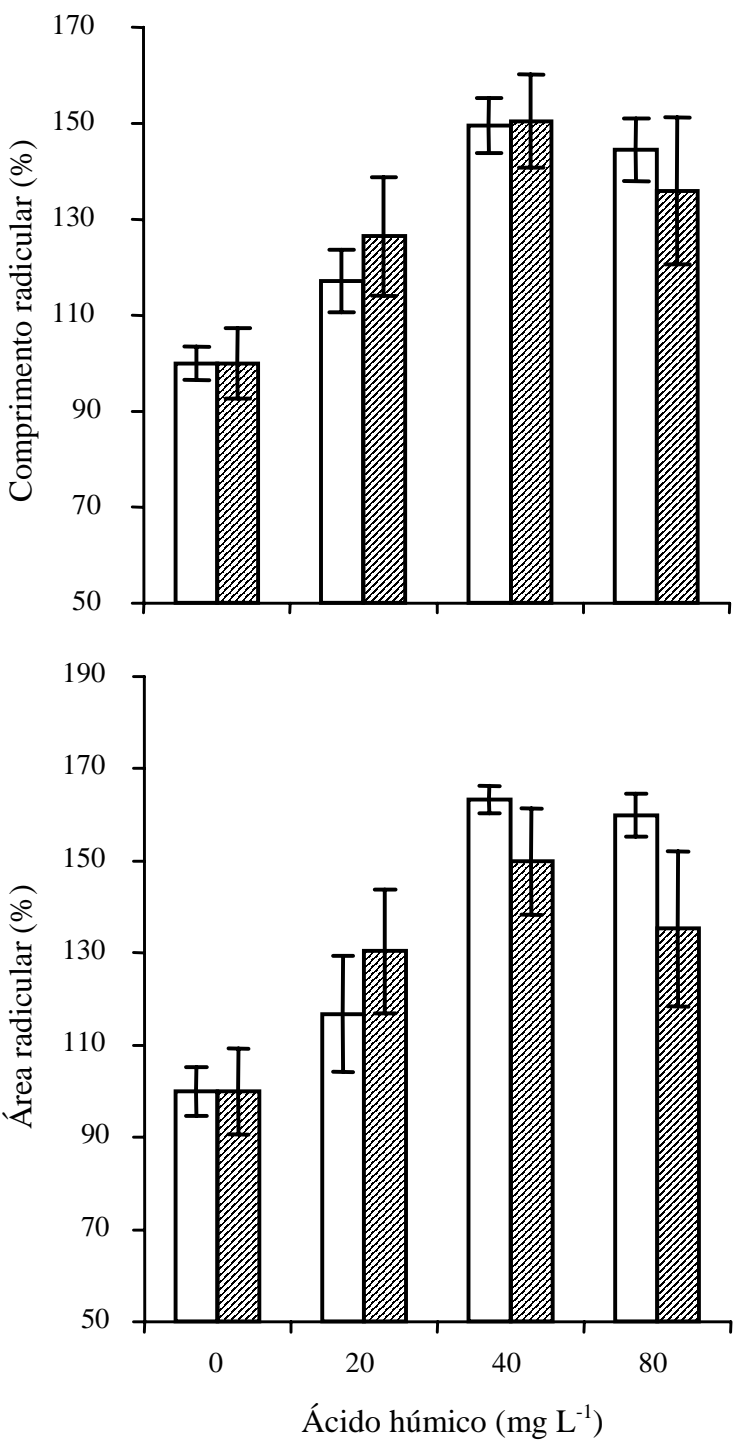

Figura 2. Efeito estimulatório (em porcentagem em relação ao controle) sobre o comprimento e área radiculares de plântulas de café e de milho tratadas com diferentes concentrações de ácidos húmicos (AH) extraídos de lodo da estação de tratamento de esgoto (barras brancas) e de vermicomposto (barras hachuradas). Os dados representam a média de seis experimentos independentes com milho $(n=120)$ e de quatro experimentos com café $(n=80)$ e seus respectivos intervalos de confiança da média $(\mathrm{p}=0,05)$. 
condição para o aumento da plasticidade da parede celular e a conseqüente elongação da célula vegetal, esse fenômeno tem sido associado à ação de auxinas, promovendo ativação da $\mathrm{H}^{+}$-ATPase por meio de mecanismos que ainda não foram completamente elucidados (Rayle \& Cleland, 1992). Portanto, o aumento do desenvolvimento radicular em resposta ao tratamento com AHL e AHV pode estar relacionado à estimulação da atividade da $\mathrm{H}^{+}$-ATPase de membrana plasmática observada nas preparações de vesículas extraídas de plântulas tratadas com esses AH (Tabela 3). Esse estímulo parece resultar de uma superexpressão da enzima na membrana plasmática evidenciada pela maior quantidade de $\mathrm{H}^{+}$-ATPase detectada imunologicamente nas vesículas isoladas tanto de plântulas de milho como nas de café, tratadas com ambos AH (Figura 4). Esse dado reforça a idéia de um envolvimento direto dos grupamentos auxínicos dos AH (Figura 1) na ativação da $\mathrm{H}^{+}$-ATPase, desde que foi demonstrado que a incubação de tecidos de milho com auxina induz um aumento do número de $\mathrm{H}^{+}$-ATPases expressas na membrana plasmática (Frias et al., 1996).

Comparativamente, foram observadas diferenças significativas entre os AH no estímulo da atividade hidrolítica da $\mathrm{H}^{+}$-ATPase de membrana plasmática.

Tabela 3. Atividades de hidrólise de ATP (vanadato sensível) e de transporte de prótons mediados pela $\mathrm{H}^{+}$-ATPase de membrana plasmática, expressos por suas velocidades iniciais (médiasterro-padrão). As vesículas foram isoladas de raízes de café e milho crescidas na ausência (controle) e na presença de $40 \mathrm{mg} \mathrm{L}^{-1}$ de ácidos húmicos extraídos de lodo da estação de tratamento de esgoto (AHL) e de vermicomposto (AHV). Os valores de velocidade inicial do transporte de prótons estão apresentados em unidades arbitrárias de fluorescência por minuto $\left(\mathrm{F} \mathrm{min}^{-1}\right)^{(1)}$.

\begin{tabular}{|c|c|c|c|c|}
\hline \multirow[t]{2}{*}{ Tratamento } & \multicolumn{2}{|c|}{ Preparação de raízes de café(2) } & \multicolumn{2}{|c|}{ Preparação de raízes de milho $^{(3)}$} \\
\hline & $\mu \mathrm{mol} \mathrm{P}_{\mathrm{i}} \mathrm{mg} \mathrm{min}^{-1}$ & $\mathrm{~F} \mathrm{~min}^{-1}$ & $\mu \mathrm{mol} \mathrm{P}_{\mathrm{i}} \mathrm{mg} \mathrm{\operatorname {min } ^ { - 1 }}$ & $\mathrm{F} \mathrm{min}^{-1}$ \\
\hline Controle & $1,23 \pm 0,11 \mathrm{a}$ & $80 \pm 9$ & $2,41 \pm 0,24 \mathrm{a}$ & $120 \pm 15$ \\
\hline AHL & $2,94 \pm 0,19 b$ & $250 \pm 12$ & $4,43 \pm 0,32 b$ & $270 \pm 20$ \\
\hline AHV & $2,47 \pm 0,13 c$ & $230 \pm 15$ & $3,34 \pm 0,15 c$ & $255 \pm 18$ \\
\hline
\end{tabular}

${ }^{(1)}$ Médias seguidas pela mesma letra, na coluna, não diferem entre si pelo teste t a 5\% de probabilidade. ${ }^{(2)}$ Médias de três preparações diferentes com três repetições por preparação. ${ }^{(3)}$ Médias de quatro preparações diferentes com três repetições por preparação.
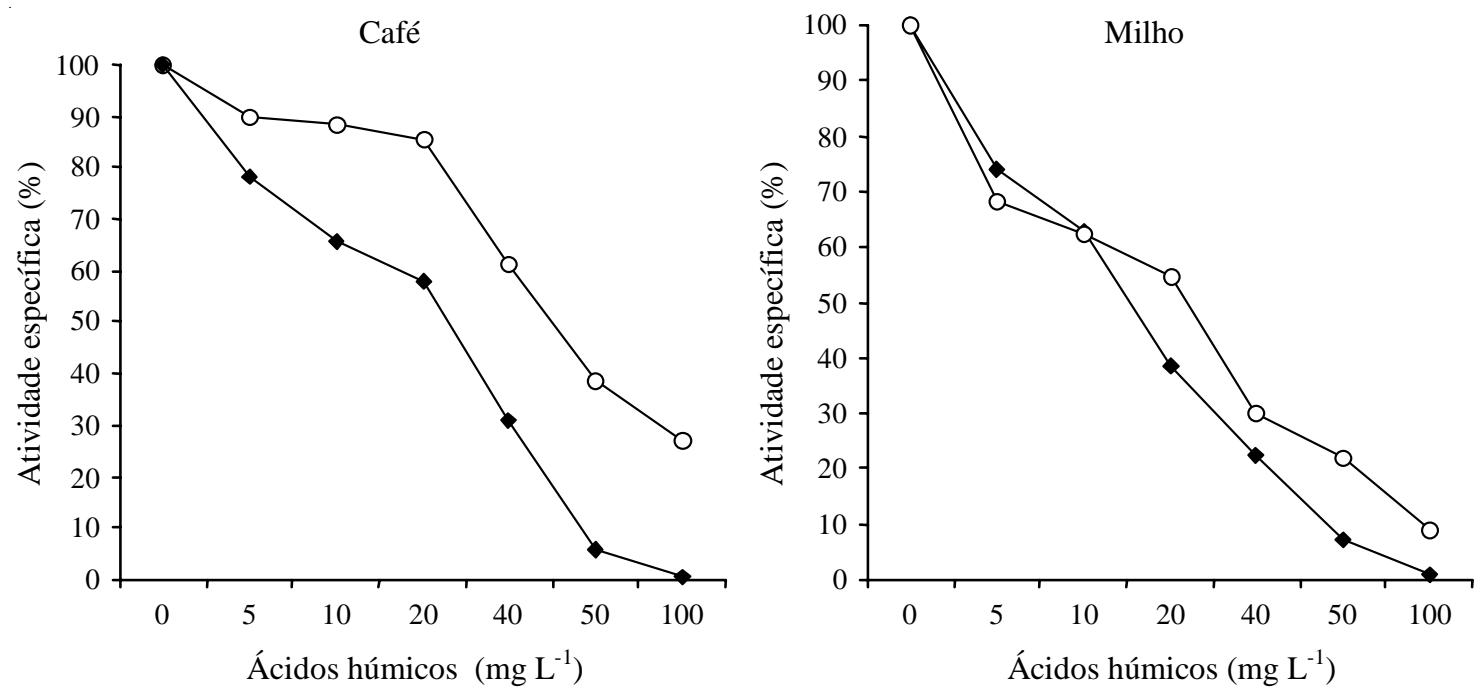

Figura 3. Ensaio in vitro da ação dos ácidos húmicos sobre a atividade específica sensível à vanadato da $\mathrm{H}^{+}$-ATPase de membrana plasmática isolada de raízes de café e milho controle (i.e., crescidas sem ácidos húmicos). O meio reacional consistiu de 50 mM MOPS-Tris pH 6,5, 100 mM KCl, 3 mM MgSO 4,1 mM ATP, 0,05 mg mL-1 de proteína e concentrações crescentes dos ácidos húmicos extraídos de vermicomposto (o) e de lodo da estação de tratamento de esgoto 


\section{AHL AHV}

a
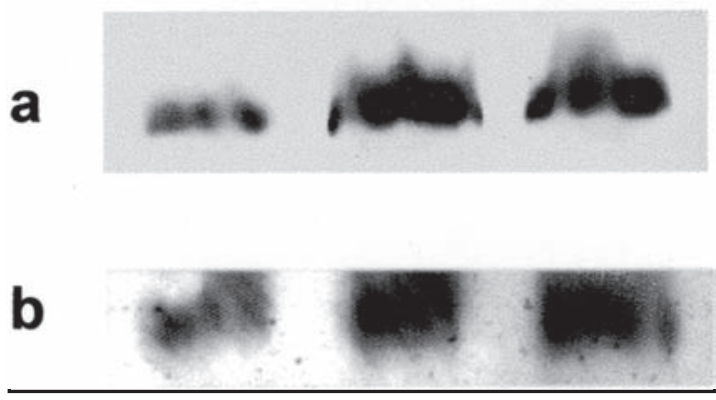

Figura 4. Diferenças no conteúdo da $\mathrm{H}^{+}$-ATPase de membrana plasmática nas preparações de raízes tratadas com ácidos húmicos isolados de lodo da estação de tratamento de esgoto (AHL), vermicomposto (AHV) e controle (C) separadas em gel SDS-PAGE a 7,5\%. O Western blot foi realizado utilizando-se anticorpos contra a $\mathrm{H}^{+}$-ATPase de membrana plasmática de Nicotiana plumbaginifolia para identificar esta enzima nas preparações de vesículas de membrana plasmática de raízes de milho (a) e de café (b).

Tanto nos experimentos com café como com milho, os AHL estimularam mais a atividade da $\mathrm{H}^{+}$-ATPase de membrana plasmática do que AHV. O gradiente de $\mathrm{H}^{+}$gerado pela ATPase nas vesículas isoladas de raízes de milho tratadas com AHL foi maior do que as tratadas com AHV, consistente com o efeito fisiológico observado no crescimento radicular (Figura 2). Outra possibilidade seria um acoplamento entre o estímulo da atividade da $\mathrm{H}^{+}$-ATPase e o aumento do transporte de nutrientes que, por sua vez, resultaria em estímulo do crescimento da planta (Pinton et al., 1999). Foi postulado, previamente, que ácidos fúlvicos poderiam dissipar o potencial elétrico da membrana plasmática, e que também promoveriam aumento gradual na permeabilidade da mesma a nutrientes. Contrário a essa hipótese, apesar de ambos os efeitos promoverem, de fato, aumento da atividade ATPásica in vitro, seria improvável que esses ácidos pudessem proporcionar qualquer efeito benéfico sobre a célula vegetal intacta, uma vez que o potencial elétrico e a permeabilidade seletiva das membranas são características indispensáveis para a homeostase e a sinalização celular.

Neste estudo, são apresentadas evidências experimentais que suportam um possível mecanismo de ação para a bioatividade dos $\mathrm{AH}$, envolvendo uma atividade hormonal expressa por grupamentos funcionais específicos dos AH sobre o sistema de transporte primário de prótons da membrana plasmática da célula vegetal. A coincidência entre estímulo no desenvolvimento do sistema radicular do milho e do café com ambos os $\mathrm{AH}$, e o estímulo observado na atividade da $\mathrm{H}^{+}$-ATPase e na síntese da enzima, é uma evidência bioquímica bastante consistente do efeito fisiológico de $\mathrm{AH}$ sobre o crescimento das plantas. Os alvos moleculares primariamente envolvidos na interação SH-célula vegetal e as vias de sinalização envolvidas neste processo serão objeto de futuras investigações.

\section{Conclusões}

1. A interação planta e ácidos húmicos $(\mathrm{AH})$ promove a redistribuição das faixas de tamanho moleculares dos AH em solução, consistente com a mobilização de subunidades funcionais dos AH por substâncias exsudadas pelas raízes.

2. A presença de grupamentos auxínicos na estrutura de ambos os AH estudados sugere uma relação entre a indução e a ativação da $\mathrm{H}^{+}$-ATPase de membrana plasmática com a atividade hormonal dos ácidos húmicos.

3. A ativação da $\mathrm{H}^{+}$-ATPase de membrana plasmática pode estar relacionada com o incremento da área radicular ao promover a acidificação do apoplasto e o conseqüente aumento da plasticidade da parede celular.

4. A presença de grupamentos funcionais com características hormonais e a capacidade de ativar a bomba de prótons da membrana plasmática são indicadores potenciais da bioatividade dos ácidos húmicos.

\section{Agradecimentos}

À Faperj (E26-619/150-99), à Fenorte e ao CNPq (465918/00-0), pelo apoio financeiro.

\section{Referências}

BOTTOMLEY, W. B. Some effects of organic-promotion substances (auximones) on the growth of Lema minor in 
mineral cultural solutions. Proceedings of the Royal Society of London Series B Biological Sciences, London, v. 89, p. 481-505, 1917.

CANELLAS, L. P.; GURIDI, F.; SANTOS, G. de A.; RUMJANEK, V. M.; BRAZ-FILHO, R. Aumento da resolução de espectros de $\mathrm{RMN}{ }^{13} \mathrm{C}$ com uso de $\mathrm{KCl}$ 0,03 mol L ${ }^{-1}$. Química Nova, São Paulo, v. 24, p. 131$132,2001$.

CANELLAS, L. P.; SANTOS, G. de A.; MORAES, A. A.; OLIVARES, F. L.; RUMJANEK, V. M. Avaliação das características de ácidos húmicos extraídos de resíduos urbanos. I. Métodos espectroscópicos (Uv-vis, IV, RMN ${ }^{13} \mathrm{C}-\mathrm{CP} / \mathrm{MAS}$ ) e microscopia eletrônica de varredura. $\mathbf{R e}-$ vista Brasileira de Ciência do Solo, Viçosa, MG, v. 24, p. 741-750, 2000a.

CANELLAS, L. P.; SANTOS, G. de A.; MORAES, A. A.; RUMJANEK, V. M. Avaliação das características de ácidos húmicos extraídos de resíduos urbanos. II. Métodos termodegradativos (pirólise acoplada à cromatografia gasosa-espectrometria de massas). Revista Brasileira de Ciência do Solo, Viçosa, MG, v. 24, p. 751-754, 2000 b.

COZZOLINO, A.; CONTE, P.; PICCOLO, A. Conformational changes of humic substances induced by some hydroxy-, keto-, and sulfonic acids. Soil Biology $\boldsymbol{\&}$ Biochemistry, Oxford, v. 33, p. 563-571, 2001.

CRUVINEL, P. E.; CRESTANA, S.; JORGE, L. A. C. Métodos e aplicações do processamento de imagens digitais. In: CRESTANA, S.; CRUVINEL, P. E.; MASCARENHAS, S.; BISCEGLI, C. I.; MARTINNETO, L.; COLGNAGO, L. A. (Ed.). Instrumentação agropecuária: contribuições no limiar do novo século. Brasília: Embrapa-SPI, 1996. p. 91-151.

DE MICHELIS, M. I.; SPANSWICH, R. M. $\mathrm{H}^{+}$-pumping driven by vanadate sensitive ATPase in membrane vesicles from corn roots. Plant Physiology, Rockville, v. 81, p. 542-547, 1986.

FAÇANHA, A. R.; DE MEIS, L. Inhibition of maize root $\mathrm{H}^{+}$-ATPase by fluoride and fluoroaluminate complexes. Plant Physiology, Rockville, v. 108, p. 241-246, 1995.

FRIAS, I.; CALDEIRA, M. T.; PEREZ, C. J. R.; NAVARRO, A. J. P.; CULIANEZ, M. F. A.; KUPPINGER, O.; STRANSKY, H.; PAGES, M.; HAGER, A.; SERRANO, R. A major isoform of the maize plasma membrane $\mathrm{H}^{+}$-ATPase: characterization and induction by auxin in coleoptiles. Plant Cell, Rockville, v. 8, p. 15331544, 1996.
GUMINSKI, S. Present days view on physiological effects induced in plant organisms by humic compounds. Soviet Soil Science, Moscow, v. 9, p. 1250-1255, 1968.

GURIDI, F. O fósforo, o café, a matéria orgânica e a microrriza. 2000. 150 f. Tese (Doutorado) - Universidade Federal Rural do Rio de Janeiro, Seropédica.

LOWRY, O. H.; ROSEBROUGH, N. J.; FARR, A. L.; RANDALL, R. J. Protein measurement with the folin phenol reagent. Journal of Biological Chemistry, Bethesda, v. 193, p. 265-275, 1951.

MORSOMME, P.; BOUTRY, M. The plant plasma membrane $\mathrm{H}^{+}$-ATPase: structure, function and regulation. Biochimica et Biophysica Acta, Amsterdam, v. 1465, n. 1/ 2, p. 1-16, 2000.

MUSCOLO, A.; CUTRUPI, S.; NARDI, S. IAA detection in humic substances. Soil Biology and Biochemistry, Oxford, v. 30, p. 1199-1201, 1998.

NANNIPIERI, P.; GREGO, S.; DELL'AGNOLA, G.; NARDI, S. Proprietà biochimiche e fisiologiche della sostanza organica. In: NANNIPIERI, P. (Ed.). Ciclo della sostanza organica nel suolo: aspetti agronomici, chimici, ecologici, ecologici \& selvicolturali. Bologna: Patron, 1993. p. 67-78.

NARDI, S.; CONCHERI, G.; DELL'AGNOLA, G.; SCRIMIN, P. Nitrate uptake and ATPase activity in oat seedlings in the presence of two humic fractions. Soil Biology \& Biochemistry, Oxford, v. 23, p. 833-836, 1991.

NARDI, S.; PIZZEGHELlO, D.; GESSA, G.; FERRARESE, L.; TRAINOTTI, L.; CASADORO, G. A low molecular weight humic fraction on nitrate uptake and protein synthesis in maize seedlings. Soil Biology \& Biochemistry, Oxford, v. 32, p. 415-419, 2000.

NARDI, S.; PIZZEGHELLO, D.; RENIERO, F.; MUSCOLO, A. Biological activity of humic substances extracted from soils under different vegetation cover. Communications in Soil Science and Plant Analysis, New York, v. 30, p. 621-634, 1999.

PICCOlO, A.; CONTE, P.; COZZOLINO, A. Conformational association of dissolved humic substances as affected by interactions with mineral and monocarboxylic acids. European Journal of Soil Science, Oxford, v. 50, p. 687-694, 1999. 
PINTON, R.; CESCO, S.; IACOLETTIG, G.; ASTOLFI, S.; VARANINI, Z. Modulation of $\mathrm{NO}_{3}^{-}$uptake by waterextractable humic substances: involvement of root plasma membrane $\mathrm{H}^{+}$-ATPase. Plant and Soil, Dordrecht, v. 215, p. 155-161, 1999.

RAYLE, D. L.; CLELAND, R. E. The acid growth theory of auxin-induced cell elongation is alive and well. Plant Physiology, Rockville, v. 99, p. 1271-1274, 1992.

SANTOS, G. de A.; CAMARGO, F. A. O. Fundamentos da matéria orgânica: ecossistemas tropicais e subtropicais. Porto Alegre: Gênesis, 1999. p. 69-90.

SCHNITZER, M.; PRESTON, C. M. Analysis of humic acids by solution and solid state carbon-13 nuclear magnetic resonance. Soil Science Society of America Journal, Madison, v. 50, p. 326-333, 1986.
VARANINI, Z.; PINTON, R.; DE BIASE, M. G.; ASTOLFI, S.; MAGGIONI, A. Low molecular weight humic substances stimulate $\mathrm{H}^{+}$-ATPase activity of plasma membrane vesicles isolated from oat (Avena sativa $\mathrm{L}$.) roots. Plant and Soil, Dordrecht, v. 153, p. 61-69, 1993.

VAUGHAN, D.; MALCOLM, R. E. Influence of humic substances on growth and physiological process. In: VAUGHAN, D.; MALCOLM, R. E. (Ed.). Soil organic matter and biological activity. Dordrecht: Kluwer Academic, 1985. p. 37-75.

ZECH, W.; SENESI, N.; GUGGENBERGER, G.; KAISER, K.; LEHMANN, J.; MIANO, T. M.; MILTNER, A.; SCHROTH, G. Factors controlling humification and mineralization of soil organic matter in the tropics. Geoderma, Amsterdam, v. 79, p. 117-161, 1997. 